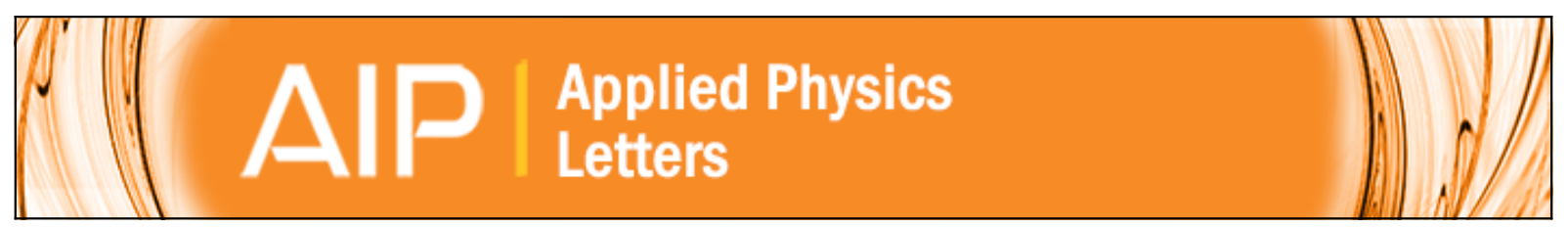

\title{
Minority carrier lifetime in iodine-doped molecular beam epitaxy-grown $\mathrm{HgCdTe}$
}

I. Madni, G. A. Umana-Membreno, W. Lei, R. Gu, J. Antoszewski, and L. Faraone

Citation: Applied Physics Letters 107, 182107 (2015); doi: 10.1063/1.4935154

View online: http://dx.doi.org/10.1063/1.4935154

View Table of Contents: http://scitation.aip.org/content/aip/journal/apl/107/18?ver=pdfcov

Published by the AIP Publishing

\section{Articles you may be interested in}

Direct and phonon-assisted indirect Auger and radiative recombination lifetime in $\mathrm{HgCdTe}$, InAsSb, and InGaAs computed using Green's function formalism

J. Appl. Phys. 118, 015702 (2015); 10.1063/1.4923059

Minority carrier lifetime in type-2 InAs-GaSb strained-layer superlattices and bulk $\mathrm{HgCdTe}$ materials

Appl. Phys. Lett. 97, 052108 (2010); 10.1063/1.3476352

Effects of hydrogen on majority carrier transport and minority carrier lifetimes in long wavelength infrared $\mathrm{HgCdTe}$ on $\mathrm{Si}$

Appl. Phys. Lett. 88, 062106 (2006); 10.1063/1.2172295

Effect of dislocations on minority carrier lifetime in $\mathrm{HgCdTe}$

J. Appl. Phys. 95, 2467 (2004); 10.1063/1.1644039

Analysis of carrier concentration, lifetime, and electron mobility on p-type $\mathrm{HgCdTe}$

J. Appl. Phys. 83, 2586 (1998); 10.1063/1.367019

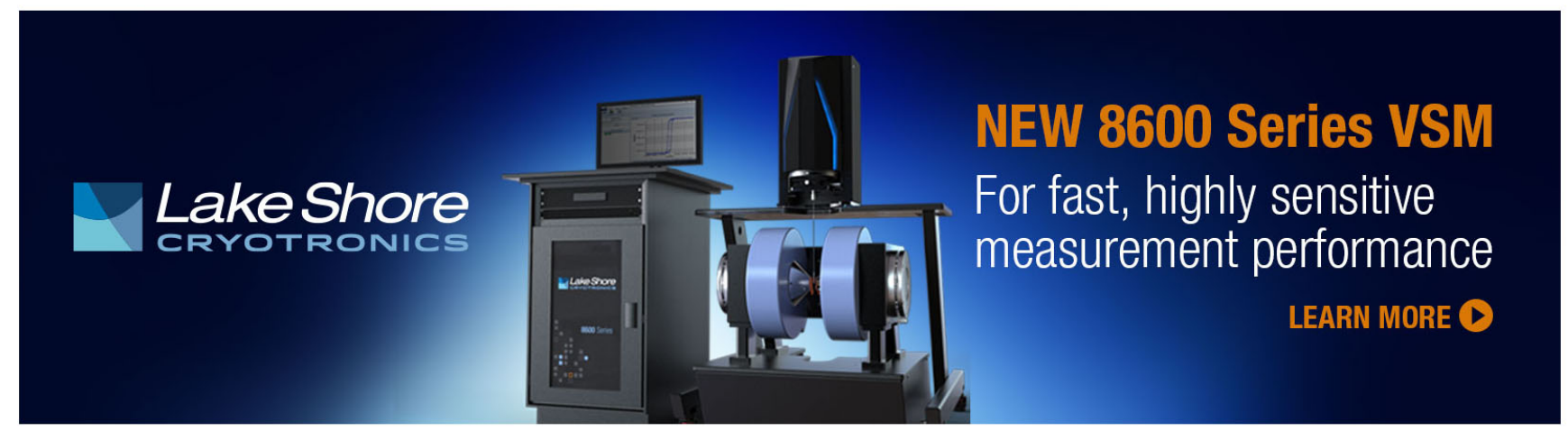




\title{
Minority carrier lifetime in iodine-doped molecular beam epitaxy-grown $\mathrm{HgCdTe}$
}

\author{
I. Madni, G. A. Umana-Membreno, W. Lei, R. Gu, J. Antoszewski, and L. Faraone \\ School of Electrical, Electronic and Computer Engineering, The University of Western Australia, Crawley, \\ Western Australia 6009, Australia
}

(Received 14 August 2015; accepted 22 October 2015; published online 6 November 2015)

\begin{abstract}
The minority carrier lifetime in molecular beam epitaxy grown layers of iodine-doped $\mathrm{Hg}_{1-\mathrm{x}} \mathrm{Cd}_{\mathrm{x}} \mathrm{Te}$ ( $\mathrm{x} \sim 0.3$ ) on $\mathrm{CdZnTe}$ substrates has been studied. The samples demonstrated extrinsic donor behavior for carrier concentrations in the range from $2 \times 10^{16} \mathrm{~cm}^{-3}$ to $6 \times 10^{17} \mathrm{~cm}^{-3}$ without any postgrowth annealing. At a temperature of $77 \mathrm{~K}$, the electron mobility was found to vary from $10^{4} \mathrm{~cm}^{2} /$ $\mathrm{V}$ s to $7 \times 10^{3} \mathrm{~cm}^{2} / \mathrm{V}$ s and minority carrier lifetime from $1.6 \mu \mathrm{s}$ to $790 \mathrm{~ns}$, respectively, as the carrier concentration was increased from $2 \times 10^{16} \mathrm{~cm}^{-3}$ to $6 \times 10^{17} \mathrm{~cm}^{-3}$. The diffusion of iodine is much lower than that of indium and hence a better alternative in heterostructures such as $\mathrm{nBn}$ devices. The influence of carrier concentration and temperature on the minority carrier lifetime was studied in order to characterize the carrier recombination mechanisms. Measured lifetimes were also analyzed and compared with the theoretical models of the various recombination processes occurring in these materials, indicating that Auger-1 recombination was predominant at higher doping levels. An increase in deep-level generation-recombination centers was observed with increasing doping level, which suggests that the increase in deep-level trap density is associated with the incorporation of higher concentrations of iodine into the HgCdTe. C 2015 AIP Publishing LLC.

[http://dx.doi.org/10.1063/1.4935154]
\end{abstract}

HgCdTe-based infrared (IR) detectors have wideranging applications in various defence and civilian sectors due to their superior performance resulting from high optical absorption coefficient, high carrier mobility, long minority carrier lifetime, and corresponding high responsivity. Among these electronic parameters, minority carrier lifetime is one of the primary factors that determine device performance, due to its direct impact on quantum efficiency. In $\mathrm{HgCdTe}$ materials, the minority carrier lifetime is a function of material chemical composition, defect types and density, conductivity type, and carrier concentration. Some work has been undertaken to study the minority carrier lifetime in indium (In) doped $n$-type $\mathrm{HgCdTe}$, and Lopes et al. have reviewed the data on lifetime reported in In-doped longwavelength IR (LWIR) $\mathrm{HgCdTe}$ materials. ${ }^{1}$ At carrier concentrations up to $5 \times 10^{15} \mathrm{~cm}^{-3}$, the lifetime was observed to range from $0.4 \mu \mathrm{s}$ to $8 \mu \mathrm{s}$, depending on the chemical composition of the material and the defects therein. ${ }^{2-4}$ Recent measurements of minority carrier lifetime reported by Swartz et al., ranging from $2.5 \mu \mathrm{s}$ to $5 \mu \mathrm{s}$ in LWIR $\mathrm{HgCdTe}$ materials, suggest that the lifetime is limited by defects. ${ }^{5}$ This is due to the low carrier concentration in these reported samples $\left(\sim 10^{15}\right)$, such that the minority carrier lifetime was dominated by the Shockley-Read-Hall (SRH) recombination mechanism (trap-assisted), whereas the Auger and radiative recombination mechanisms were less effective.

It is worth noting that in contrast to the studies reporting on minority carrier lifetime in In-doped $\mathrm{HgCdTe}$, very limited data are available for iodine-doped $\mathrm{HgCdTe}$. Ross investigated iodine doping in $\mathrm{HgCdTe}$ by direct alloy growth (DAG) using metal-organic chemical vapour deposition (MOCVD). ${ }^{6}$ They reported that the memory effect during MOCVD growth using iodine doping was $\sim 100$ times lower than for indium doping. Also, the diffusion coefficient for iodine was reported to be $<1 \times 10^{-13} \mathrm{~cm}^{2} / \mathrm{s}$, which is significantly lower than the $10^{-11}-10^{-10} \mathrm{~cm}^{2} / \mathrm{s}$ reported for indium. ${ }^{7,8}$ Therefore, iodine provides an effective $n$-type dopant for growing $\mathrm{HgCdTe}$ heterostructures requiring abrupt $\mathrm{p}-\mathrm{n}$ junction or doped-undoped concentration profiles, such as $n$-type-Barrier- $n$-type $(\mathrm{nBn}) \mathrm{HgCdTe}$ detector structures. The electron concentration at $77 \mathrm{~K}$ is linearly proportional to the dopant partial pressure from $5 \times 10^{15}$ to $2 \times 10^{18} \mathrm{~cm}^{-3}$. This doping range is as wide as that of indium doping. In this work, we present a study on the minority carrier lifetime in iodine-doped $n$-type mid-wave IR HgCdTe materials grown by molecular beam epitaxy (MBE). The minority carrier lifetime was found to decrease with increasing doping concentration and, based on the temperature dependent behaviour of minority carrier lifetime, the dominant carrier recombination mechanisms were also analysed for different doping levels.

Single layers of $\mathrm{HgCdTe}$ were grown on $\mathrm{CdZnTe}$ substrates in a Riber 32P MBE system. The HgCdTe layers were doped in situ with iodine during the MBE growth process using a $\mathrm{CdI}_{2}$ precursor. To investigate the effect of doping concentration on the minority carrier lifetime, three samples, A, B, and C, with different doping concentrations, were grown using different temperatures for the $\mathrm{CdI}_{2}$ dopant cell. The doping details and material characteristics of samples A, B, and C are summarized in Table I. Infrared transmission spectra were used to analyze the chemical composition and thickness of the $\mathrm{HgCdTe}$ epitaxial layers. The carrier mobility and carrier concentrations were obtained from Hall effect measurements in van der Pauw configuration at cryogenic temperatures using a variable magnetic field from 0 to $2 \mathrm{~T}$. Minority carrier lifetimes were 
TABLE I. Electronic properties of $\mathrm{n}-\mathrm{HgCdTe}$ samples doped with different iodine concentrations.

\begin{tabular}{|c|c|c|c|c|c|c|c|}
\hline Sample & $\begin{array}{c}\mathrm{CdI}_{2} \text { cell } \\
\text { temperature }\left({ }^{\circ} \mathrm{C}\right)\end{array}$ & $\begin{array}{c}\mathrm{Hg}_{1-\mathrm{x}} \mathrm{Cd}_{\mathrm{x}} \mathrm{Te} \\
\text { X-value }\end{array}$ & $\begin{array}{l}\mathrm{Hg}_{1-\mathrm{x}} \mathrm{Cd}_{\mathrm{x}} \mathrm{Te} \\
\text { thickness }(\mu \mathrm{m})\end{array}$ & $\begin{array}{l}\text { XRD (FWHM) } \\
\text { arc sec }\end{array}$ & $\begin{array}{l}\text { Electron concentration } \\
\quad \text { at } 77 \mathrm{~K}\left(\mathrm{~cm}^{-3}\right)\end{array}$ & $\begin{array}{c}\text { Electron mobility } \\
\text { at } 77 \mathrm{~K}\left(\mathrm{~cm}^{2} / \mathrm{V}^{-1} \mathrm{~s}^{-1}\right)\end{array}$ & $\begin{array}{l}\text { Lifetime } \\
\text { at } 77 \mathrm{~K}(\mu \mathrm{s})\end{array}$ \\
\hline A & 110 & 0.28 & 2.6 & 53 & $2.12 \times 10^{16}$ & 10856 & 1.6 \\
\hline B & 130 & 0.29 & 2.7 & 78 & $8.84 \times 10^{16}$ & 8466 & 1.04 \\
\hline $\mathrm{C}$ & 150 & 0.30 & 2.8 & 51 & $6.02 \times 10^{17}$ & 6688 & 0.75 \\
\hline
\end{tabular}

measured using the photoconductive decay technique. Note that no post-growth annealing or surface passivation layer were applied on any of the samples. In all cases, based on the known laser power, for photoconductive decay measurements, beam spot size, sample layer thickness, and delay time, the calculated excess carrier concentrations was kept well below $5 \times 10^{14}$. ${ }^{9}$ Hence, it was assumed that low-level injection conditions were satisfied and, thus, the injection level did not influence the measurements. To avoid sweepout effects, the sample biasing was kept low $(300 \mathrm{mV})$, and all photoconductive decay curves were fitted exponentially to obtain the minority carrier lifetimes. ${ }^{10}$

Several different recombination mechanisms determine the photogenerated minority carrier lifetime in n-type $\mathrm{HgCdTe}$, such as Auger, radiative, and Shockley-Read-Hall mechanisms, which have been discussed extensively in the literature. ${ }^{9,11-16}$ We have applied these mechanisms to model the lifetime for minority carriers in our samples with relevant equations taken from the standard literature. ${ }^{10}$

The measured minority carrier lifetime, carrier mobility, and other material parameters for the iodine-doped $\mathrm{HgCdTe}$ layers in samples A, B, and C are summarized in Table I. As evident from this table, these iodine-doped layers exhibit good lifetime even at high carrier concentrations, especially considering that no post-growth annealing was applied in order to annihilate $\mathrm{Hg}$ vacancies. The electron mobility at $77 \mathrm{~K}$ was found to decrease from $1 \times 10^{4} \mathrm{~cm}^{2} \mathrm{~V}^{-1} \mathrm{~s}^{-1}$ for an electron concentration of $2.1 \times 10^{16} \mathrm{~cm}^{-3}$, to $6.7 \times 10^{3}$ $\mathrm{cm}^{2} \mathrm{~V}^{-1} \mathrm{~s}^{-1}$ for an electron concentration of $6 \times 10^{17} \mathrm{~cm}^{-3}$. The carrier concentrations were extracted from the measured Hall coefficient data under varying magnetic field: that is, from -2 to $0 \mathrm{~T}$ and from 0 to $2 \mathrm{~T}$.

The extracted lifetime values, from the temperature dependent photoconductive decay measurement results, are illustrated in Fig. 1 for the three investigated samples with varying iodine electron concentration. Generally, the three samples present long minority carrier lifetimes at low temperatures. As the temperature is increased from $77 \mathrm{~K}$, minority carrier lifetime first increases slightly and then decreases exponentially at higher temperatures. For example, for sample A, the minority carrier lifetime increases from $1.6 \mu \mathrm{s}$ at $77 \mathrm{~K}$ to $1.9 \mu \mathrm{s}$ at $150 \mathrm{~K}$, and then decreases exponentially to $75 \mathrm{~ns}$ at $250 \mathrm{~K}$. Such a temperature-dependent behaviour for minority carrier lifetime is quite typical for direct band gap materials like $\mathrm{HgCdTe}{ }^{17,18}$ As the temperature is increased, the intrinsic carrier concentration increases with increasing temperature, thus reducing the Auger lifetime. At low temperatures, the temperature-independent lifetime is due to a combination of Auger and/or SRH scattering. The small increase in lifetime for the mid-temperature range is due to a shift in the Fermi level $\left(\mathrm{E}_{\mathrm{f}}\right)$ relative to the energy levels of the dominant traps associated with SRH recombination. Since SRH levels tend to follow the valence band with an increase in temperature, whereas $\mathrm{E}_{\mathrm{f}}$ moves toward the conduction band, this results in a decrease in the SRH recombination rate and a slight increase in minority carrier lifetime. At higher temperatures, the lifetime decreases exponentially due to the dominance of Auger-1 recombination, as observed in Figure 1.

As expected, the lifetime was found to decrease with increasing carrier concentration in samples B and C. The behaviour of the lifetime vs temperature for various concentrations of iodine in $\mathrm{HgCdTe}$ samples $\mathrm{A}, \mathrm{B}$, and $\mathrm{C}$ is shown in Figure 1. At $77 \mathrm{~K}$, the lifetime decreased from $1.6 \mu$ s to $750 \mathrm{~ns}$ when the carrier concentration increased from 2.12 $\times 10^{16} \mathrm{~cm}^{-3}$ to $6 \times 10^{17} \mathrm{~cm}^{-3}$.

In order to determine the dominant recombination mechanisms, the effective total minority carrier lifetime in $\mathrm{HgCdTe}$ was modelled by taking into account the following mechanisms: Auger recombination ( $\left.\tau_{\text {Auger }}\right)$, Shockley-Read-Hall recombination $\left(\tau_{\mathrm{SRH}}\right)$, and Radiative recombination $\left(\tau_{\text {Radiative }}\right)$ : $1 / \tau_{\text {total }}=1 / \tau_{\text {radiative }}+1 / \tau_{\text {Auger }}+1 / \tau_{\text {SRH }}{ }^{9,12,14-16}$ The value of the overlap integral $\left|F_{1} F_{2}\right|$ was taken as $0.15 .{ }^{19}$ As a representative example, Fig. 2 shows the modelled and experimental data for the investigated sample A. Generally, the band-toband recombination lifetime $\left(\tau_{\text {Auger }}\right.$ and $\left.\tau_{\text {Radiative }}\right)$ is a strong function of temperature, due to both mechanisms being inversely proportional to the square of intrinsic carrier concentration. As the temperature is increased, the free electron density remains essentially constant initially, but then increases rapidly in the intrinsic regime. At higher temperatures, Auger recombination is the dominant process due to the high carrier density, which causes a rapid decrease of minority carrier lifetime. However, the lifetime data for these HgCdTe layers cannot be

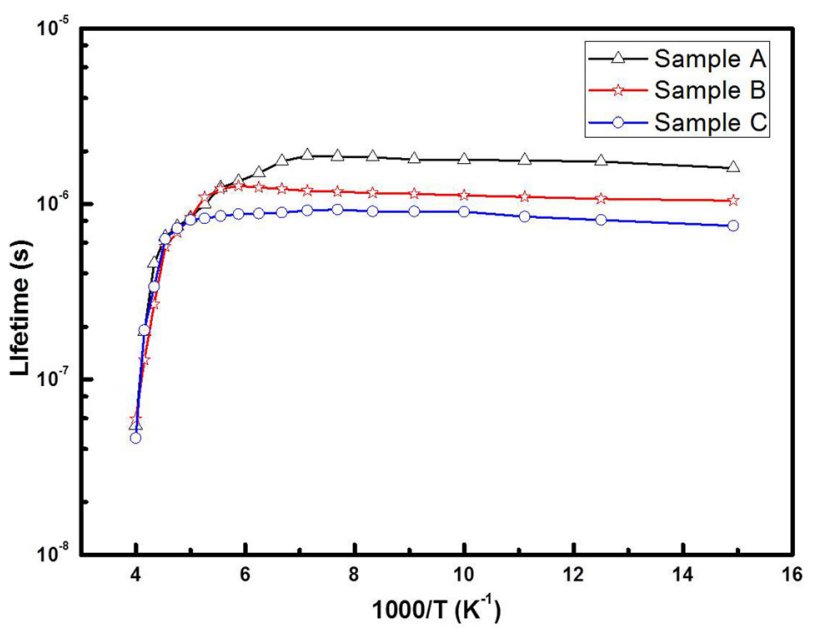

FIG. 1. Minority carrier lifetime for samples A, B, and C as a function of temperature. 


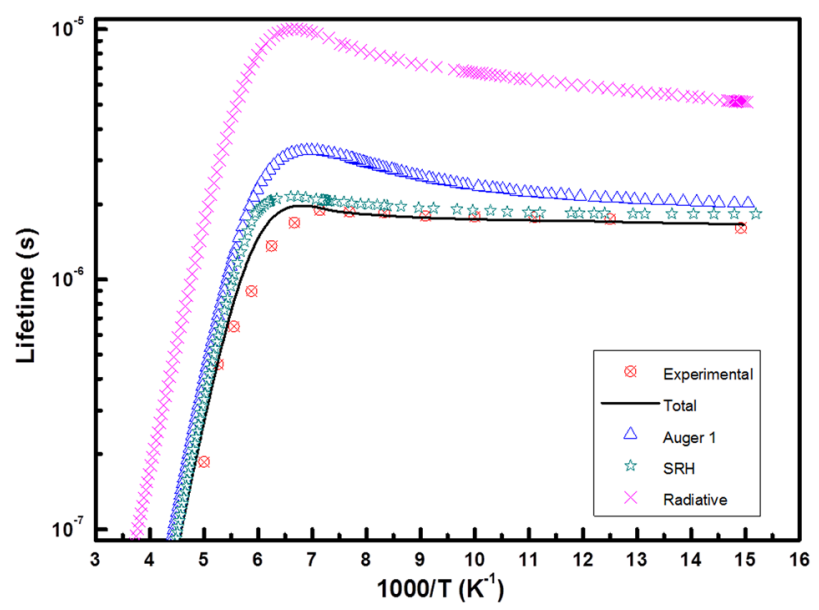

FIG. 2. Experimental and theoretical lifetime as a function of inverse temperature for sample A.

explained by only band-to-band recombination processes, since it is necessary to include SRH recombination mechanism to obtain a good fit to the experimental data. Results show that for the lower carrier concentration in sample A, SRH recombination processes become important in addition to the band-toband Auger-1 process. Typically, as-grown $\mathrm{HgCdTe}$ layers contain $\mathrm{Hg}$ vacancies and, consequently, some level of compensation exists which could play an important role in the $\mathrm{SRH}$ recombination process. Inevitably, such $\mathrm{Hg}$ vacancies exist in all three investigated samples, but their impact on minority carrier lifetimes in samples B and $\mathrm{C}$ is limited due to the relatively high carrier density and, consequently, shorter Auger lifetime.

The SRH limited lifetime is predominant in the extrinsic temperature range, whereas Auger lifetime becomes progressively more important in the intrinsic temperature range. At higher temperatures, parallel combinations of SRH and Auger-1 recombination cause lifetimes to decrease exponentially with increasing temperature. The results indicate a significant dependence of Auger lifetime on the Fermi level, which is heavily affected by temperature and carrier concentration, and also affected considerably by the position of the extrinsic impurity energy level in the forbidden gap. Lifetime data from Kinch and Buss have indicated that the defect level is at $30 \mathrm{meV}$ above the valence band, ${ }^{20}$ whereas other researchers have argued that the defect level is slightly deeper. ${ }^{21}$ In our case, lifetime data on $\mathrm{HgCdTe}$ show a best fit to calculations when the dominant recombination centre is assumed to be $0.42 \mathrm{Eg}$ above the valence band. $^{22}$

A significant difference in the dominant recombination mechanisms was observed between the three samples, as shown in Fig. 3. Only the charge neutral defects with defect energies near the Fermi level and with low formation energies were considered when modelling $\tau_{\mathrm{SRH}}$. The Te-antisite $\left(\mathrm{Te}_{\mathrm{Cd}}\right)$ has two defect levels near mid-gap. ${ }^{23}$ Similar to $\mathrm{CdTe}, \mathrm{HgCdTe}$ is grown under tellurium rich conditions and has formation energy of almost $1 \mathrm{eV}$. Therefore, it is very likely that a significant concentration of $\mathrm{Te}_{\mathrm{Cd}}$ defects will be created when the growth is under Te rich conditions. Defect densities and capture cross sections for holes and electrons were extracted by fitting with experimental lifetime data and are presented in Table II.

In addition to Te-related and native vacancy defects, it is reasonable to expect that at higher doping levels, iodine atoms may form complexes with other impurity atoms or Te interstitials and other point defects. This defect formation has been explained in another paper, where structural aspects

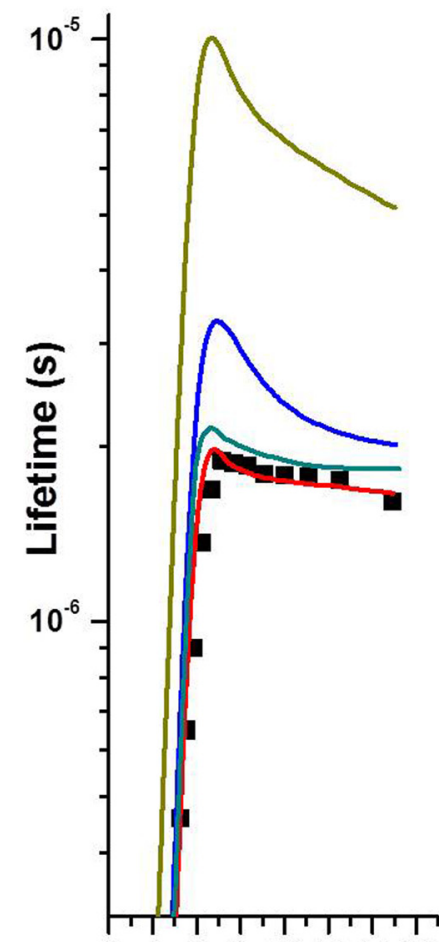

246810121416

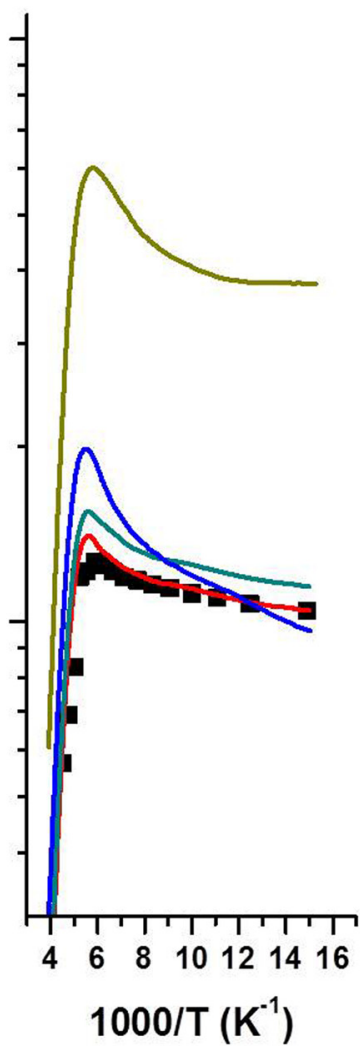

FIG. 3. Comparison of experimental minority carrier lifetime and the calculated Auger-1, radiative, SRH, and total lifetime for samples A, B, and C. 
TABLE II. Samples A, B, and C with deep level trap parameters obtained from fitting the experimental data.

\begin{tabular}{|c|c|c|c|c|c|c|c|}
\hline Sample No. & $\mathrm{X}$-value & $\begin{array}{l}\text { Carrier concentration } \\
\qquad\left(\mathrm{Cm}^{-3}\right)\end{array}$ & $\begin{array}{c}\text { Etch pit } \\
\text { density }\left(\mathrm{cm}^{-3}\right)\end{array}$ & $\begin{array}{l}\text { Lifetime } \\
\quad(\mu \mathrm{s})\end{array}$ & $\begin{array}{l}\text { Trap density } \\
\left(\mathrm{cm}^{-3}\right)\end{array}$ & $\begin{array}{l}\text { Electron capture } \\
\text { cross-section }\left(\mathrm{cm}^{2}\right)\end{array}$ & $\begin{array}{c}\text { Hole capture } \\
\text { cross-section }\left(\mathrm{cm}^{2}\right)\end{array}$ \\
\hline A & 0.28 & $2.12 \times 10^{16}$ & $1.6 \times 10^{5}$ & 1.6 & $6 \times 10^{14}$ & $4 \times 10^{-15}$ & $3 \times 10^{-15}$ \\
\hline B & 0.29 & $8.84 \times 10^{16}$ & $8 \times 10^{5}$ & 1.04 & $2 \times 10^{15}$ & $3.5 \times 10^{-14}$ & $6.3 \times 10^{-14}$ \\
\hline $\mathrm{C}$ & 0.30 & $6.02 \times 10^{17}$ & $1.3 \times 10^{6}$ & 0.75 & $6.5 \times 10^{15}$ & $5 \times 10^{-14}$ & $8 \times 10^{-14}$ \\
\hline
\end{tabular}

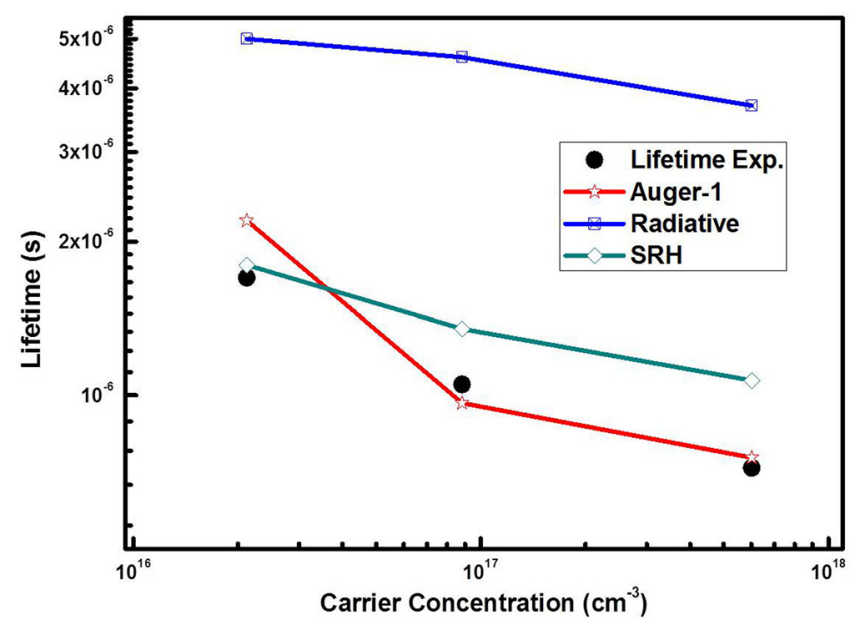

FIG. 4. Comparison of experimental and calculated lifetime at $77 \mathrm{~K}$ for samples A, B, and C.

of these samples were studied. ${ }^{24}$ All of these complexes could act as SRH recombination centres if they have welldefined energy levels within the band gap. Consequently, $\mathrm{HgCdTe}$ materials with higher iodine concentration would be expected to have a shorter SRH lifetime. Pines and Stafsudd showed that an acceptor recombination centre limits the photoconductive lifetime of $\mathrm{HgCdTe}$ when SRH lifetime dominates the Auger lifetime. ${ }^{14}$ Fig. 4 clearly indicates that at $77 \mathrm{~K}$, SRH dominates for low doped samples.

The trap density extracted by fitting the modelling results in the experimental photoconductivity data, correlated with the etch pit density (EPD) measurements that were performed on samples A, B, and C as shown in Table II. The EPD was found to increase in a well behaved manner with carrier concentration. Fig. 5 shows minority carrier lifetimes measured at $77 \mathrm{~K}$ as a function of EPD values for the three samples. It can be clearly seen that lifetime decreases with increasing EPD, with a relationship $\tau \propto 1 / \mathrm{EPD}$. This implies that if a low doping can be achieved, it is possible to grow material with a low SRH trap density. This inverse relationship between carrier concentration and EPD, and with the trap densities obtained by SRH modelling, clearly indicates that higher doping is associated with the introduction of additional SRH recombination centres, such as vacancies, antisites, impurities, or complexes. Also, Auger lifetime depends on the position of the Fermi level which, in turn, is also affected by dopant concentration, temperature, and position of the deep trap levels in the band gap.

In addition, it is noted that the investigated samples were not surface passivated, which may result in the surface properties being different from those of the bulk. The presence of any negative surface charge would lead to depletion/

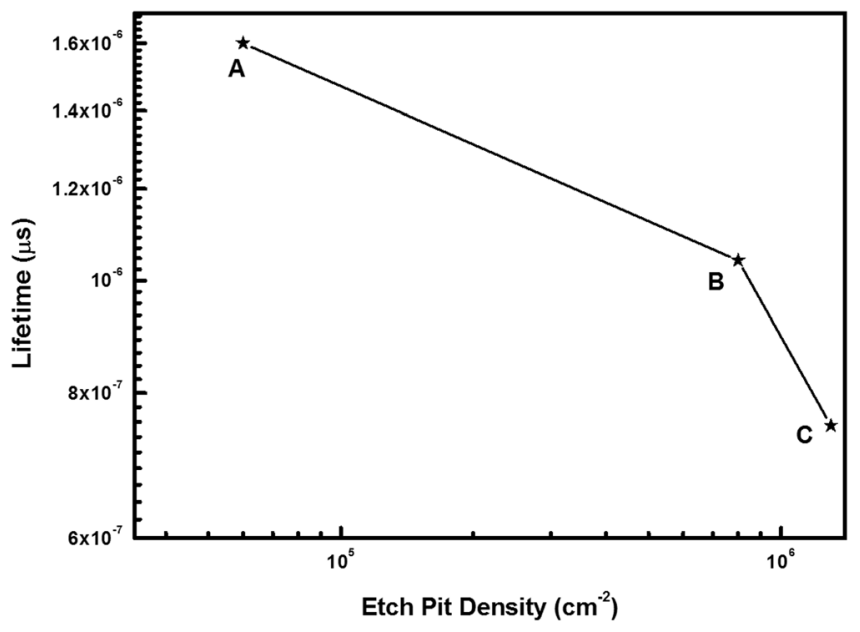

FIG. 5. Correlation between experimental lifetime and dislocation density for samples A, B, and C.

inversion of the surface, resulting in enhanced surface recombination.

Iodine acts as a promising $n$-type dopant in $\mathrm{HgCdTe}$ lattice. It is proven to have a low diffusion coefficient because it belongs to group VII and it substitutes Te lattice sites when introduced into $\mathrm{HgCdTe}$. It has a very small memory effect as compared to indium, which dedicated to high vapor pressures of its precursors. The thermal stability of Iodine is much better than that of indium and hence a better alternative in heterostructures such as nBn devices. In this work, we have studied minority carrier lifetime in iodine-doped HgCdTe layers $(\mathrm{x} \sim 0.3)$ grown by MBE. We have achieved well controlled in-situ extrinsic $n$-type doping over a wide range of concentrations during MBE growth of $\mathrm{HgCdTe}$. The iodine doped HgCdTe layers demonstrate carrier mobility as high as $1 \times 10^{4} \mathrm{~cm}^{2} \mathrm{~V}^{-1} \mathrm{~s}^{-1}$ and minority carrier lifetime as long as $1.6 \mu \mathrm{s}$ without any post-growth annealing. The effect of increasing carrier concentration was also investigated. It was found that minority carrier lifetime at low temperatures was limited by SRH recombination for comparatively low doping levels, while the Auger recombination mechanism limited lifetime in samples with higher carrier concentration. However, SRH still plays an important role, even at higher carrier concentration levels. More work is required before an unambiguous interpretation of the photogenerated minority carrier lifetime in iodine doped $\mathrm{HgCdTe}$ grown by MBE will be possible.

Financial support from Australian Research Council (FT130101708 and DP120104835), Go8-DAAD joint research cooperation scheme (2014-2015), and the Faculty of Engineering, Computing and Mathematics at University 
of Western Australia is gratefully acknowledged. Facilities used in this work are supported by the WA node of Australian National Fabrication Facility (ANFF).

${ }^{1}$ V. C. Lopes, A. J. Syllaios, and M. C. Chen, "Minority carrier lifetimes in mercury cadmium telluride," Semicond. Sci. Technol. 8, 824 (1993).

${ }^{2}$ R. G. Pratt, J. Hewett, P. Capper, C. L. Jones, and M. J. Quelch, "Minority carrier lifetime in $n$-type Bridgman grown $\mathrm{Hg}_{1-\mathrm{x}} \mathrm{Cd}_{\mathrm{x}} \mathrm{Te}$," J. Appl. Phys. 54, 5152 (1983).

${ }^{3}$ W. H. Wright, V. C. Lopes, and A. J. Syllaios, "Measurements of the surface recombination velocity of $(\mathrm{Hg}, \mathrm{Cd}) \mathrm{Te}$," Proc. SPIE 1107, 212 (1989).

${ }^{4}$ V. C. Lopes, W. H. Wright, and A. J. Syllaios, "Characterization of (Hg,Cd)Te by the photoconductive decay technique," J. Vac. Sci. Technol., A 8, 1167 (1990).

${ }^{5}$ C. H. Swartz, R. P. Tompkins, N. C. Giles, T. H. Myers, D. D. Edwall, J. Ellsworth, E. Piquette, J. Arias, M. Berding, S. Krishnamurthy, I. Vurgaftman, and J. R. Meyer, "Fundamental materials studies of undoped, In-doped, and As-doped $\mathrm{Hg}_{1-\mathrm{x}} \mathrm{Cd}_{\mathrm{x}} \mathrm{Te}$," J. Electron. Mater. 33, 728 (2004).

${ }^{6} \mathrm{~B}$. Ross, "Survey of literature on minority carrier lifetimes in silicon and related topics," in Lifetime Factors in Silicon, ASTM Special Technical Publication Vol. 712 (American Society for Testing and Materials, Philadelphia, 1980), pp. 14-28.

${ }^{7}$ S. Murakami, T. Okamoto, K. Maruyama, and H. Takigawa, "Iodine doping in mercury cadmium telluride $\left(\mathrm{Hg}_{1-\mathrm{x}} \mathrm{Cd}_{\mathrm{x}} \mathrm{Te}\right)$ grown by direct alloy growth using metalorganic chemical vapor deposition," Appl. Phys. Lett. 63(7), 899 (1993).

${ }^{8}$ M. Brown and A. F. W. Willoghby, "Diffusion in $\mathrm{Cd}_{\mathrm{x}} \mathrm{Hg}_{1-\mathrm{X}} \mathrm{Te}$ and related materials," J. Cryst. Growth 59, 27 (1982).

${ }^{9}$ S. E. Schacham and E. Finkman, "Recombination mechanisms in p-type HgCdTe: Freezeout and background flux effects," J. Appl. Phys. 57, 2001 (1985).

${ }^{10}$ See supplementary material at http://dx.doi.org/10.1063/1.4935154 for theoretical models for lifetime calculations and an example of exponential fit of photoconductive decay data.
${ }^{11}$ M. A. Kinch, M. J. Brau, and A. Simmons, "Recombination mechanisms in 8-14- $\mu \mathrm{m}$ HgCdTe," J. Appl. Phys. 72, 4261 (1992).

${ }^{12}$ J. S. Blakemore, Semiconductor Statistics (Pergaman, New York, 1962), p. 196.

${ }^{13}$ I. M. Baker, F. A. Capocci, D. E. Charlton, and J. T. M. Wotherspoon, "Recombination in cadmium mercury telluride photodetectors," SolidState Electron. 21, 1475 (1978).

${ }^{14}$ M. Y. Pines and O. M. Stafsudd, "Recombination process in intrinsic semiconductors using impact ionization capture cross sections in indium antimonide and mercury cadmium telluride," Infrared Phys. 20, 73 (1980).

${ }^{15}$ W. Shockley and W. T. Read, "Statistics of the recombinations of holes and electrons," Phys. Rev. 87, 835 (1952).

${ }^{16}$ C. T. Sah and W. Shockley, "Electron-hole recombination statistics in semiconductors through flaws with many charge conditions," Phys. Rev. 109, 1103 (1958).

${ }^{17}$ R. K. Willardson and A. C. Ben, Semiconductor and Semimetals (Academic Press, New York, 1967), Vol. 3, p. 499.

${ }^{18}$ P. E. Petersen, “Auger recombination in $\mathrm{Hg}_{1-x} \mathrm{Cd}_{\mathrm{x}}$ Te," J. Appl. Phys. 41, 3465 (1970)

${ }^{19}$ P. G. Maloney, R. Dewames, J. G. Pellegrino, C. Billman, J. M. Arias, D. D. Edwall, D. Lee, and J. Khurgin, "Measurement of minority carrier lifetime in $n$-type MBE HgCdTe on variable substrates," J. Electron. Mater. 41(10), 2785 (2012).

${ }^{20}$ M. A. Kinch and D. D. Buss, "The physics of semimetals and narrow-gap semiconductors," J. Phys. Chem. Solids 32, 461 (1971).

${ }^{21}$ M. Y. Pines, O. M. Stafsudd, and P. B. Bratt, "Characteristics of n-type mercury cadmium telluride," Infrared Phys. 19, 633 (1979).

${ }^{22}$ D. L. Polla and R. L. Aggarwal, "Below band-gap photoluminescence of $\mathrm{Hg}_{1-\mathrm{x}} \mathrm{Cd}_{\mathrm{x}}$ Te," Appl. Phys. Lett. 44(8), 775 (1984).

${ }^{23}$ R. H. Vydyanath, J. C. Donovan, and D. A. Nelson, "Lattice defects in semiconducting $\mathrm{Hg}_{1-\mathrm{x}} \mathrm{Cd}_{\mathrm{x}} \mathrm{Te}$ alloys, III. Defect structure of undoped $\mathrm{Hg}_{0.8} \mathrm{Cd}_{0.2}$ Te," J. Electrochem. Soc. 11, 111 (1981).

${ }^{24}$ I. Madni, R. J. Gu, W. Lei, J. Antoszweski, and L. Faraone, "Structural and electrical properties of iodine doped $\mathrm{Hg}_{1-\mathrm{x}} \mathrm{Cd}_{\mathrm{x}} \mathrm{Te}$ films grown by MBE," in Proceedings of the IEEE Conference on Optoelectronic and Microelectronic Materials and Devices (COMMAD), Perth WA, 14-17 December 2014, pp. 90-93. 